\title{
Inhibition of human neutrophils by auranofin: chemotaxis and metabolism of arachidonate via the 5-lipoxygenase pathway
}

\author{
J ELMGREEN, ${ }^{1}$ I AHNFELT-R $\varnothing N$ I $^{2},^{2}$ AND O H NIELSEN ${ }^{3}$
}

From the ${ }^{1}$ Department of Rheumatology TTA, Rigshospitalet, University of Copenhagen; the ${ }^{2}$ Department of Pharmacology, Leo Pharmaceutical Products; and the ${ }^{3}$ Department of Medical Gastroenterology C, Herlew Hospital, University of Copenhagen, Denmark

SUMMARY The effect of auranofin on human neutrophil (PMN) 5-lipoxygenase activity and leucotriene $\mathrm{B}_{4}\left(\mathrm{LTB}_{4}\right)$ chemotaxis was investigated. $\left[1-{ }^{14} \mathrm{C}\right]$ Arachidonic acid was incorporated into the purified cells until steady state conditions were obtained. After preincubations with seriab dilutions of auranofin arachidonic acid release and metabolism were stimulated with calcium ionophore A23187. The radioactive eicosanoids released were extracted and separated by thirg layer chromatography, followed by autoradiography and quantitative laser densitometry Chemotaxis of PMNs towards $\mathrm{LTB}_{4}$ was measured in a modified Boyden chamber. Auranofipe showed dose dependent inhibition of both the 5-lipoxygenase pathway $\left(\mathrm{IC}_{50} 17 \cdot 4 \times 10^{-6}\right.$ molkl $)$ and of chemotaxis $\left(\mathrm{IC}_{50} 45 \times 10^{-6} \mathrm{~mol} / \mathrm{l}\right)$. The release of arachidonic acid from phospholipids wa unaffected in the concentration range tested $(1-1000 \mu \mathrm{mol} / \mathrm{l})$. Inhibition of both neutrop零ib motility and cellular synthesis of proinflammatory eicosanoids may thus contribute to the beneficial clinical effects of auranofin in rheumatoid arthritis.

Key words: inflammation, leucotrienes, rheumatoid arthritis.

In rheumatoid arthritis the polymorphonuclear neutrophil granulocyte (PMN) is of potential importance for modulation of the inflammatory process. ${ }^{1}$ This cell type may constitute more than $90 \%$ of the cellular exudate in synovial fluid ${ }^{2}$ and is abundant in the inflamed synovial membrane and at the interface of cartilage with pannus. ${ }^{3}$ Local secretion of arachidonic acid metabolites, formed mainly via the 5 -lipoxygenase pathway, ${ }^{45}$ oxygen free radicals, ${ }^{6}$ and lysosomal enzymes, especially natural proteases, may be essential for perpetuation of inflammation and for tissue destruction. ${ }^{7}$

PMNs from patients with rheumatoid arthritis show an enhanced capacity for metabolism of endogenous arachidonic acid, with increased release of leucotriene $\mathrm{B}_{4}\left(\mathrm{LTB}_{4}\right)$ during activation in vitro. ${ }^{8}$ Accordingly, high concentrations of $\mathrm{LTB}_{4}$ are found in the synovial fluid from patients with active

Accepted for publication 23 June 1988

Correspondence to $\mathrm{Dr} \mathrm{O} \mathrm{H}$ Nielsen, Department of Medical Gastroenterology C, Herlev Hospital, University of Copenhagen, Herlev Ringvej, DK-2730 Herlev, Denmark. rheumatoid arthritis. ${ }^{45}{ }^{5} \mathrm{LTB}_{4}$ is a proinflammatory mediator, which activates human PMNs with respect. to chemotaxis and aggregation, ${ }^{10}{ }^{11}$ and, further, it is a complete secretagogue in PMNs, showing physiological profile similar to that of calciun? ionophore A23187. ${ }^{12}$ Thus inhibitors of $\mathrm{LTB}_{4}$ syn? thesis and $\mathrm{LTB}_{4}$ actions may show anti-inflam@ matory properties.

Auranofin, a new gold compound for oral treat? ment of rheumatoid arthritis, ${ }^{13}$ has been shown to affect many of the activities of PMNs in acute. inflammation. ${ }^{14}$ The aim of the present work was tow discover whether auranofin affected two essentia? functions of PMNs in relation to chronic nons specific inflammation-namely, metabolism ot endogenous arachidonic acid mainly via the 5-lipoxygenase pathway to $\mathrm{LTB}_{4}$ and 5-hydroxye eicosatetraenoic acid (5-HETE), and chemotaxi to $\mathrm{LTB}_{4}$ itself, which is elicited via specific sur? face receptors.

Materials and methods

Blood was drawn in $10 \mathrm{mM}$ edetic acid from $2 \mathscr{Q}$ 
healthy volunteers who had taken no drugs, including salicylates, for at least four weeks.

Neutrophils were isolated by a modification of Böyum's method ${ }^{15}$ including: sedimentation of erythrocytes with methylcellulose $(0 \cdot 8 \%)$, gradient centrifugation of 'buffy coat' leucocytes on Lymphoprep (Nygaard and Co, Oslo, Norway), and hypotonic lysis of residual erythrocytes. The final cell suspensions contained more than $95 \%$ PMNs, with a median recovery of $44 \%$. The viability was $97 \%$, as shown by the trypan blue exclusion test.

\section{DRUGS AND CHEMOATTRACTANT}

Shortly before use serial dilutions were made in Gey's solution ( $\mathrm{pH} 7 \cdot 2-7 \cdot 4)$ of auranofin (1-1000 $\mu \mathrm{mol} / \mathrm{l})$ (mol. wt 678.5) (Smith, Kline and French, Solna, Sweden) dissolved in $\mathbf{0} \cdot \mathbf{1} \%$ ethanol. Nordihydroguaiaretic acid $(10 \mu \mathrm{mol} / \mathrm{l})$ (Sigma Inc, St Louis, MO, USA), a well established inhibitor of 5lipoxygenase activity, was included as a control. The amount and purity of $\mathrm{LTB}_{4}$ (Paesel GmbH, Frankfurt am Main, FRG) was checked by an ultraviolet spectrum and by high pressure liquid chromatography, which showed a purity of more than $95 \%$.

\section{ARACHIDONATE METABOLISM}

Isolated PMNs were incubated with [1${ }^{14} \mathrm{C}$ ]arachidonic acid $\left(37000 \times 10^{3} \mathrm{~Bq} / 5 \times 10^{6}\right.$ cells, $2.2 \times 10^{9} \mathrm{~Bq} / \mathrm{mmol}$ ) (Amersham International, Buckinghamshire, UK) for five hours at $37^{\circ} \mathrm{C}$ to obtain steady state labelling of intracellular pools of arachidonic acid. ${ }^{16}$ Non-incorporated extracellular arachidonic acid was remöved by washing. Test drug was then added to the cells 1-30 minutes before stimulation with calcium ionophore A23187 (Calbiochem, La Jolla, CA, USA) (15 minutes) in an optimal concentration of $10 \mu \mathrm{mol} / \mathrm{l} .^{16}$ Extracellular fluid containing radiolabelled metabolites was prepared by instantaneous removal of the cells by centrifugation ( $8000 \mathrm{~g}$, one minute) through dibuthyl phthalate:dinonyl phthalate 3:1 (density $1.033 \mathrm{~g} / \mathrm{ml}$ ) before extraction of eicosanoids. ${ }^{16} 17$

The radioactive metabolites were then separated by thin layer chromatography and measured by autoradiography and laser densitometry as previously described. ${ }^{16}$ Fractions more lipophilic than arachidonic acid were not included in the calculations.

Identification of arachidonic acid and metabolites was carried out with cochromatography using pure standards (Paesel GmbH, Frankfurt am Main, FRG), and evaluation of specific activities by high pressure liquid chromatography has been described in detail previously. ${ }^{16}$ The concentration of auranofin necessary for $50 \%$ inhibition of arachidonic acid catabolism $\left(\mathrm{IC}_{50}\right)$ via the 5-lipoxygenase pathway was calculated by intrapolation from the logarithmic dose-response curves.

\section{REVERSIBILITY AN D VIABILITY}

In a separate series of six experiments [1${ }^{14} \mathrm{C}$ ]arachidonic acid labelled PMNs were incubated with auranofin $(31 \mu \mathrm{mol} / \mathrm{l})$ for 15 minutes. One half of the aliquots was then challenged with A23187, whereas the other half was washed three times in Gey's medium before challenge. The percentage viability of the PMNs was assessed before and after the incubation.

\section{CHEMOTAXIS OF NEUTROPHILS}

Cells $\left(2 \times 10^{6} / \mathrm{ml}\right)$ were added to the cellular compartment of modified Boyden chambers and migration proceeded in $3 \mu \mathrm{m}$ pore size filters (Sartorius Inc, Göttingen, FRG) for 45 minutes at $37^{\circ} \mathrm{C} .{ }^{11}$ An optimal concentration of $\mathrm{LTB}_{4}(10 \mathrm{nmol} / \mathrm{l})$, which earlier had been shown to be a potent chemoattractant, was chosen as activating agent. ${ }^{11}$ Serial dilutions of test drugs were added to the cell compartments. Results were based on analyses of five randomly selected fields in each of two replicate filters by the leading front technique. ${ }^{18}$ Chemotaxis was corrected for spontaneous migration towards Gey's solution.

Inhibition of PMN migration by auranofin was expressed as an $\mathrm{IC}_{50}$ value (the drug concentration needed to suppress chemotaxis by $50 \%$ ). 'Spontaneous' PMN migration towards Gey's solution was subtracted before analysis of the logarithmic doseresponse curves by intrapolation. Casein $(5 \mathrm{~g} / \mathrm{l})^{19}$ was included as a further positive control in all experiments.

\section{Results}

METABOLISM OF ENDOGENOUS

ARACHIDONIC ACID

During controlled conditions, when incubation occurred without test drugs, $\mathrm{LTB}_{4}$ constituted $8 \cdot 3 \%$ (6.9-12.0), 5-HETE $12 \cdot 3 \%(10 \cdot 8-13 \cdot 8)$, and unmetabolised arachidonic acid 58.8\% (54.0-78.1) of the released radioactivity. The remaining radioactivity consisted of other mono-HETEs and catabolites of $\mathrm{LTB}_{4}\left(20-\mathrm{OH}-\mathrm{LTB}_{4}\right.$ and $20-\mathrm{COOH}-$ $\mathrm{LTB}_{4}$ ), whereas only about $2 \%$ was cyclo-oxygenase products, tentatively defined as 12-hydroxyheptadecatrienoic acid. Release of $\mathrm{LTB}_{4}$ and 5HETE from unstimulated cells was below the detection limit $(0 \cdot 2 \%)$. Preliminary time-response experiments showed maximal inhibition by auranofin after an exposure time of 15 minutes before activation. Auranofin was an inhibitor of the 5-lipoxygenase pathway as the release of both 5-HETE and $\mathrm{LTB}_{4}$ was depressed markedly with a median $\mathrm{IC}_{50}$ value for $\mathrm{LTB}_{4}$ and 5-HETE of 17.4 $\mu \mathrm{mol} / \mathrm{l}$ (range 12.3-23.8) (Fig. 1). 
Auranofin did not inhibit the arachidonic acid release from phospholipids, indicating that it did not have a steroid-like effect on the phospholipase system (Table 1). The spontaneous release during control conditions was $1 \cdot 7 \times 10^{2} \mathrm{~Bq} / \mathrm{ml}(1 \cdot 2-2 \cdot 3)$.

The established lipoxygenase inhibitor nordihydroguaiaretic acid $(10 \mu \mathrm{mol} / \mathrm{l})$ included to validate the assay nearly abolished ( $>95 \%$ inhibition) the formation of the two 5-lipoxygenase metabolites, $\mathrm{LTB}_{4}$ and 5-HETE $(\mathrm{p}<0 \cdot 01)$.

REVERS IBILITY AND VIABILITY

The 5-lipoxygenase inhibitory effect of auranofin

Inhibition of 5-lipoxygenase (\%)

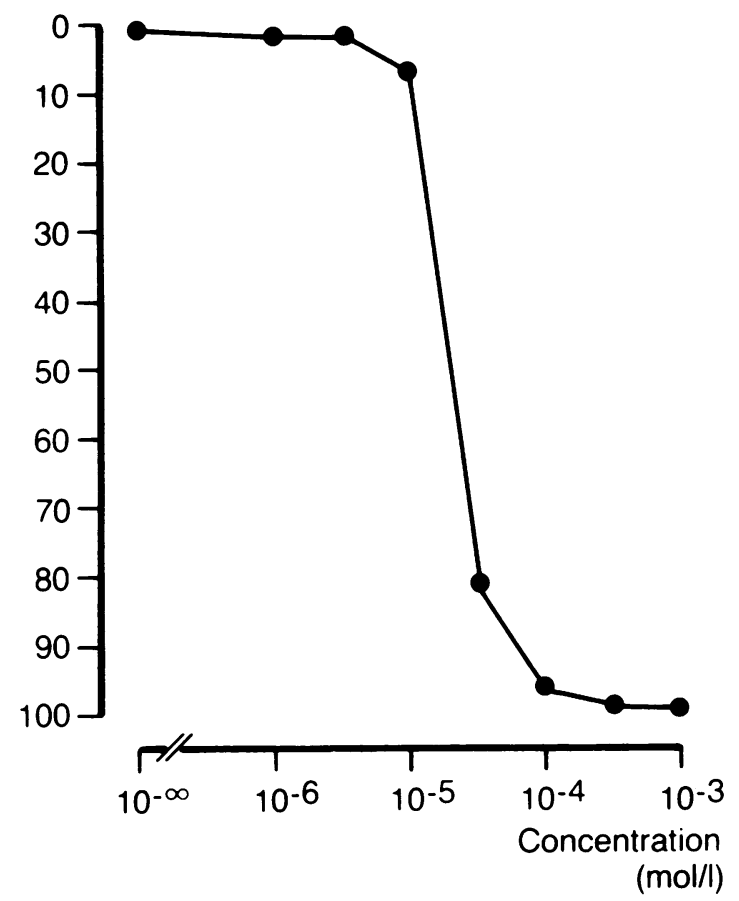

Fig. 1 Effect of auranofin at varying concentrations on release of leucotriene $B_{4}$ from activated neutrophils.

Percentage inhibition as compared with control conditions given as medians. $(n=10)$.
$(31 \mu \mathrm{mol} / \mathrm{l})$ was almost reversible. Thus an inhibition of $\mathrm{LTB}_{4}$ of $93 \%$ was obtained with this concentra? tion, and after washing four times a minor inhibition of $18 \%$ remained (range $2-33 \%$ ).

Incubation of cells with auranofin for 15 minutes in the concentration range selected did not affect the viability as more than $97 \%$ of the PMNs excludec trypan blue under these conditions.

CHEMOT A X IS
Auranofin caused complete inhibition of neutrophiP chemotaxis to $\mathrm{LTB}_{4}$ at a concentration of $316-$ $\mu \mathrm{mol} / 1$, the median $\mathrm{IC}_{50}$ value being $45 \mu \mathrm{mol} /[5$

Inhibition of chemotaxis (\%)

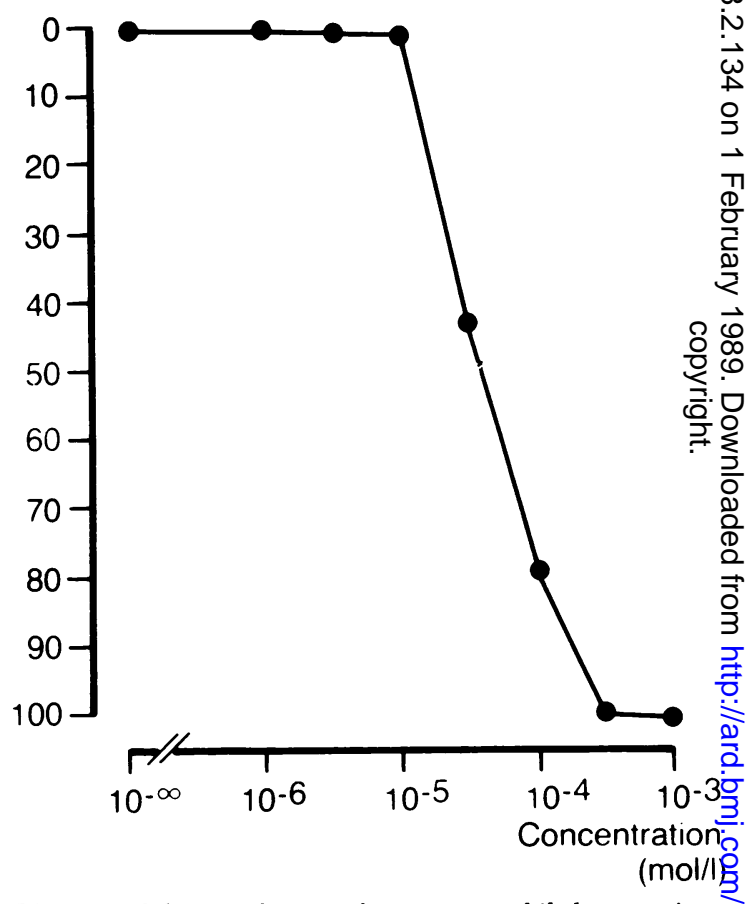

Fig. 2 Inhibition of auranofin on neutrophil chemotaxis to 0 leucotriene $B_{4}(10$ nmolll). Medians of percentage inhibition? are given for various concentrations of auranofin (ordinate). Maximum migration corrected for spontaneous migration is set to $0 \%$ of inhibition (abscissa). $(n=10)$.

Table 1 Lack of effect of auranofin on the total release of radioactivity indicating arachidonic acid and its metabolites $\left(\times 10^{2} \mathrm{~Bq} / 5 \times 10^{6}\right.$ cells $)$ during activation of neutrophils with A23187. Medians of 10 experiments are given with ranges in brackets

\begin{tabular}{llllll}
\hline & \multicolumn{2}{l}{ Concentration of auranofin (molll) } & & \\
\cline { 2 - 6 } & 0 & $10^{-6}$ & $10^{-5}$ & $10^{-4}$ & $10^{-3}$ \\
\hline Radioactivity released & $\begin{array}{l}6 \cdot 7 \\
(2 \cdot 4-9 \cdot 7)\end{array}$ & $\begin{array}{l}6 \cdot 8 \\
(2 \cdot 6-8 \cdot 9)\end{array}$ & $\begin{array}{l}6 \cdot 8 \\
(2 \cdot 2-9 \cdot 3)\end{array}$ & $\begin{array}{l}6 \cdot 5 \\
(2 \cdot 4-9 \cdot 6)\end{array}$ & $\begin{array}{c}0.8 \\
(2 \cdot 9-9 \cdot 3)\end{array}$ \\
\hline
\end{tabular}


(22-81) in 10 individual experiments (Fig. 2). Migration towards $\mathrm{LTB}_{4}(10 \mathrm{nmol} / \mathrm{l})$ and casein $(5 \mathrm{~g} / \mathrm{l})$, constituting the positive control, was $102 \mu \mathrm{m} /$ $45 \mathrm{~min}(58-130)$ and $83 \mu \mathrm{m} / 45 \mathrm{~min}(52-124)$ respectively. Spontaneous migration towards Gey's solution was $27 \mu \mathrm{m} / 45 \min (16-38)$.

\section{Discussion}

The clinical effect of auranofin in rheumatoid arthritis has been demonstrated in several investigations. ${ }^{20-22}$ During clinical situations, with a conventional dose of auranofin of $6 \mathrm{mg} /$ day, the serum concentration of auranofin is approximately $1 \mu \mathrm{mol} / 1,{ }^{23}$ and the concentration of gold compounds in synovial fluid is assumed to be in the range of $1.5-112.0 \mu \mathrm{mol} / \mathrm{l}$, with a median of $29 \mu \mathrm{mol} / 1 .{ }^{24}$ Thus the concentration range selected for the present investigation was of pharmacological relevance.

When endogenous arachidonate metabolism was investigated in purified human PMNs it was shown that auranofin was a potent inhibitor of the 5lipoxygenase activity. The $\mathrm{IC}_{50}$ values for production of the two main eicosanoids, 5-HETE and $\mathrm{LTB}_{4}$, were identical-17-18 $\mu \mathrm{mol} / \mathrm{l}$-which is well within the therapeutic range of auranofin during conventional treatment. These values are a little higher than the 5-lipoxygenase inhibition described by Parente et al using f-Met-Leu-Phe and cytochalasin $\mathrm{B}$ as challenger for the PMNs. ${ }^{25}$ They found a significant inhibition of approximately $50 \%$ (the IC $_{50}$ value was not calculated) at $5.8 \mu \mathrm{mol} / \mathrm{l}$ of auranofin. Methodological problems may account for this minor discrepancy.

Calcium ionophore A23187 was chosen for these arachidonic acid studies as 5-lipoxygenase shows an absolute requirement for calcium, ${ }^{26}$ and $\mathrm{A} 23187$ is assumed to produce the maximal synthesis of leucotrienes in response to calcium influx. The sensitivity of the present 5-lipoxygenase assay did not allow measurement of the markedly lower synthesis of 5-lipoxygenase products from PMNs challenged with the physiological stimuli-for example, immune complexes. ${ }^{27}$ As it has been reported that the potency of some 5-lipoxygenase inhibitors-for example, benoxaprofen, is dependent on the cell stimulus, whereas the potency of others-for example, BW755c, is not ${ }^{28}$ it was decided to study the effect of auranofin on a functional aspect of a physiological stimulus associated with 5-lipoxygenase activation-namely, chemotaxis of PMNs in response to $\mathrm{LTB}_{4}$; the action by $\mathrm{LTB}_{4}$ being qualitatively similar to that of A23187. ${ }^{28}$

The influence of auranofin on neutrophil chemo- taxis has earlier been studied using the agarose technique, and it was found that PMNs preincubated with auranofin migrated a shorter distance than controls when stimulated with serum or bacterial factors - that is, cytotoxins with different nonspecific receptors on cell surfaces. ${ }^{14}$ The present study using the highly purified eicosanoid $\mathrm{LTB}_{4}$, activating PMNs through specific surface receptors, ${ }^{29}$ gave an $\mathrm{IC}_{50}$ value of $45 \mu \mathrm{mol} / \mathrm{l}$ with auranofin, again a value within the therapeutic range of auranofin concentrations.

In summary, the present results suggest that locally recruited PMNs may be inhibited by auranofin, leading to a minimised production of tissue destructive and proinflammatory mediators, such as $\mathrm{LTB}_{4}$ and 5-HETE. Furthermore, auranofin may reduce the migration of PMNs from circulating blood to the affected joints. Thus the inflammation may be further reduced by auranofin because PMNs apart from producing inflammatory active eicosanoids also have the potential for release of tissue destructive oxygen free radicals. ${ }^{30}$

The authors are grateful to Helma Furhauge. Hanne Kargaard, and Bente Nielsen for skilful technical assistance. This study was supported by grants from handelsgartner Ove Villiam Buhl Olesen's and aegtefaelle Edith Buhl Olesen's Foundation, Else and Mogens Wedell-Wedellsborg's Foundation. Direktør Jacob Madsen's and hustru Olga Madsen's Foundation, and the Danish Medical Research Council.

\section{References}

1 Weissmann G. Activation of neutrophils and the lesions of rheumatoid arthritis. J Lab Clin Med 1982: 100: 322-33.

2 Palmer D G. Total leukocyte enumeration in pathologic synovial fluids. Am J Clin Pathol 1968: 49: 812-4.

3 Mohr W. Westerhellweg H. Wessinghage D. Polymorphonuclear granulocytes in rheumatic tissue destruction. III. An electron microscopic study of PMNs at the pannus-cartilage junction in rheumatoid arthritis. Ann Rheum Dis 1981; 40: 396-9.

4 Klichstein L B. Shapleigh C. Goetzl E J. Lipoxygenase of arachidonic acid as a source of polymorphonuclear leukocyte chemotactic factors in synovial fluid and tissue in rheumatoid arthritis and spondylarthritis. $J$ Clin Invest 1980; 66: 1166-70.

5 Henderson B. Higgs G A. Moncada S. Salmon J A. Synthesis of eicosanoids by tissues of the synovial joint during the development of chronic erosive synovitis. Agents Actions 1986; 17: $360-2$.

6 Ward P. Johnson K J. Till G O. Oxygen radicals, neutrophils, and acute tissue injury. In: Taylor A E. Matalon S, Ward P. eds. Physiology of oxygen radicals. Baltimore: Williams and Wilkins. 1986: 145-50.

7 Weissmann G. Lysosomal mechanisms of tissue injury in arthritis. $N$ Engl J Med 1972; 286: 141-7.

8 Elmgreen J. Nielsen OH. Ahnfelt-Rønne I. Enhanced capacity for release of leucotriene $B_{4}$ by neutrophils in rheumatoid arthritis. Ann Rheum Dis 1987; 46: 501-5.

9 Davidson E M. Rae S A. Smith M J H. Leukotriene $B_{4}$, a mediator of inflammation present in synovial fluid in rheumatoid arthritis. Ann Rheum Dis 1983; 42: 677-9.

10 Ford-Hutchinson A W. Bray M A. Doig M V. Shipley M E. Smith $M J$ H. Leukotriene $B_{4}$. a potent chemokinetic and 


\section{Elmgreen, Ahnfelt-Rønne, Nielsen}

aggregating substance released from polymorphonuclear leukocytes. Nature 1980; 286: 264-5.

11 Nielsen $\mathrm{O}$ H, Elmgreen J. Activation of neutrophil chemotaxis by leukotriene $\mathrm{B}_{4}$ and 5-hydroxyeicosatetraenoic acid in chronic inflammatory bowel disease. Scand J Clin Lab Invest 1987; 47: 605-11.

12 Serhan C N, Radin A, Smolen J E. Korchak H, Samuelsson B, Weissmann $G$. Leukotriene $B_{4}$ is a complete secretagogue in human neutrophils: a kinetic analysis. Biochem Biophys Res Commun 1982; 107: 1006-12.

13 Abruzzo J L. Auranofin: a new drug for rheumatoid arthritis. Ann Intern Med 1986; 105: 274-6.

14 Hafström I, Udén A M, Palmblad J. Modulation of neutrophil functions by auranofin. Scand J Rheumatol 1983; 12: 97-105.

15 Böyum A. Isolation of leucocytes from human blood. Scand J Clin Lab Invest 1968; 21 (suppl 97): 9-29.

16 Nielsen $\mathrm{OH}$, Bukhave $\mathrm{K}$, Ahnfelt-Rønne I, Elmgreen J. Arachidonic acid metabolism in human neutrophils: lack of effect of cyclosporine A. Int J Immunopharmacol 1986; 8: 419-26.

17 Folch J, Lees M, Sloane-Stanley G H. A simple method for the isolation and purification of total lipids from animal tissues. J Biol Chem 1957; 226: 497-509.

18 Zigmond S H, Hirsch J G. Leukocyte locomotion and chemotaxis. New methods for evaluation. and demonstration of a cellderived chemotactic factor. J Exp Med 1973; 137: 387-410.

19 Wilkinson P C. Chemotaxis and inflammation. Edinburgh: Churchill Livingstone, 1974

20 Davis J G. Ridaura (auranofin): 1986. A Smith Kline \& French International Symposium. Scand J Rheumatol 1986; (suppl 63): $1-95$.

21 Berglöf F E. Berglöf K. Walz D T. Auranofin: an oral chrysotherapeutic agent for the treatment of rheumatoid arthritis. J Rheumatol 1978; 5: 68-74.

22 Hafström I. Auranofin in the treatment of rheumatoid arthritis patients. Clinical Trials 1983; 20: 25-37.

23 Lorber A. Experience and rationale of monitoring plasm levels of gold in rheumatoid arthritis. Agents Actions 1981: 8 (suppl): 539-73.

24 Grahame R. Billings R. Laurence M. Marks V. Wood P J Tissue gold levels after chrysotherapy. Ann Rheum Dis 1974 33: 536-9.

25 Parente J E, Wong K, Davis P. Burka J F, Percy J S. Effects ổ gold compounds on leukotriene $\mathrm{B}_{4}$, leukotriene $\mathrm{C}_{4}$ and prosta $\overrightarrow{-}$ glandin $\mathrm{E}_{2}$ production by polymorphonuclear leukocytes: J Rheumatol 1986; 13: 47-51.

26 Rouzer C A. Shimizu T. Samuelsson B. On the nature of the 5-lipoxygenase reaction in human leukocytes: characterization of a membrane-associated stimulatory factor. Proc Natl Acad̄ Sci USA 1985; 82: 7505-9.

27 Nielsen $\mathrm{O} \mathrm{H}$, Elmgreen J. Activation of neutrophil chemotaxis by leukotriene $\mathrm{B}_{4}$ and 5-hydroxyeicosatetraenoic acid in chronic $\mathrm{N}$ inflammatory bowel disease. Scand J Clin Lab Invest 1987; 47 $\vec{\omega}$ 605-11.

28 Salmon J A. Tilling L C. Moncada S. Evaluation of inhibitors oO eicosanoid synthesis in leukocytes: possible pitfall of using the calcium ionophore A23187 to stimulate 5-lipoxygenase. Pros taglandins 1985; 29: 377-85.

29 Goldman D W. Goetzl E J. Heterogeneity of human polymor을 phonuclear leukocyte receptors for leukotriene $\mathrm{B}_{4} . J$ Exp Meco 1984; 159: 1027-41.

30 Henson $\mathbf{P}$ M, Johnston R B. Tissue injury in inflammation. Oxidants, proteinases, and cationic proteins. J Clin Invest 1987.6 79: $669-74$. 